\title{
Carbonyl-protein content increases in brain and blood of female rats after chronic oxycodone treatment
}

\author{
Ruping Fan' ${ }^{1}$ Lisa M. Schrott², Stephen Snelling ${ }^{1}$, John Felty ${ }^{1}$, Derrel Graham¹', Patrick L. McGauly', \\ Thomas Arnold ${ }^{1}$ and Nadejda L. Korneeva ${ }^{1,2^{*}}$ (D)
}

\begin{abstract}
Background: Opioids are the most effective drugs commonly prescribed to treat pain. Due to their addictive nature, opioid pain relievers are now second to marijuana, ahead of cocaine with respect to dependence. Ours and other studies suggest potential toxic effects of chronic opioid administration leading to neuronal degeneration. It has been suggested that protein carbonylation may represent a sensitive biomarker of cellular degeneration. To evaluate whether prolonged oxycodone administration is associated with accumulation of protein aggregates that may contribute to neuronal degeneration we measured protein carbonylation levels in brain and also in blood plasma of rats after 30-days of $15 \mathrm{mg} / \mathrm{kg}$ daily oxycodone administration.
\end{abstract}

Results: We observed a significant increase in the level of carbonylated proteins in rat brain cortex after 30-days of oxycodone treatment compare to that in water treated animals. Also, oxycodone treated rats demonstrated accumulation of insoluble carbonyl-protein aggregates in blood plasma.

Conclusions: Our data suggests that tests detecting insoluble carbonyl-protein aggregates in blood may serve as an inexpensive and minimally invasive method to monitor neuronal degeneration in patients with a history of chronic opioid use. Such methods could be used to detect toxic side effects of other medications and monitor progression of aging and neurodegenerative diseases.

Keywords: Oxycodone, Opioid, Cortex, Oxidative stress, Integrated stress response, Carbonyl-protein, Carbonylation, Protein aggregates

\section{Background}

Opioids are a type of drugs that commonly prescribed to treat pain. Due to their addictive nature, opioid pain relievers are now second to marijuana, ahead of cocaine with respect to dependence. According to a recent study, more than 10 percent of cancer patients continue to take opioids for several months after surgery, far longer than it is clinically recommended [1].

\footnotetext{
${ }^{*}$ Correspondence: nkorne@lsuhsc.edu

${ }^{1}$ Department of Emergency Medicine, Louisiana State University Health

Sciences Center, 1501 Kings Highway, Shreveport, USA

Full list of author information is available at the end of the article
}

In 2010, a study investigating the effect of prescription opioids on brain structure of opioid dependent patients demonstrated the correlation between duration of drug use and alternations in brain functional connectivity, especially in regions responsible for impulse control, reward and motivation [2]. These changes included leukoencephalopathy, axon demyelination, and white matter lesions. Thus, it is important to monitor effect of opioid therapy on brain health status. The main methods to monitor neuronal degeneration in the brains of living people are the magnetic resonance imaging (MRI) and Positron Emission 
Tomography (PET) scans. In addition, measuring toxic protein aggregates in cerebrospinal fluid from a lumbar puncture of Alzheimer's disease patient is another method to confirm development of neuronal degeneration. However, MRI and PET scan are expensive procedures that are typically not covered by insurance. Spinal taps are invasive and may lead to health complications. Thus, development of an inexpensive and minimally invasive method is important to monitor neuronal degeneration in patients with a history of chronic opioid use. Such method could also be used to detect toxic side effects of other medication and monitor progression of aging and neurodegenerative diseases.

In general, the rate of degeneration of an individual organism depends on the cells ability to balance production of newly synthesized molecules and disposal of toxic waste. The events leading to cellular waste accumulation, in the form of protein aggregation, include oxidative stress, decreased proteasomal activity and reduced autophagy. Protein aggregation eventually manifests in cell functional decline, degeneration and apoptosis. Accumulation of protein aggregates is a common biological phenomenon, observed in different physiological and pathological conditions. Protein modification, such as carbonylation, causes major changes in protein structure and function leading to formation of protease resistant protein aggregates, which result in the loss of cell viability (reviewed in [3]). Several studies have shown also that protein carbonylation increases proportionately with increasing age of cells, organelles, and tissues in diverse species $[3,4]$. Recently, an increase in protein carbonyl content was associated with development of neurodegenerative diseases such as Alzheimer's and Parkinson's diseases, and also with cancer, cataractogenesis, atherosclerosis, diabetes, sepsis and aging (reviewed in [4]).

Ours and other studies have shown that chronic opioid administration is associated with activation of the pro-apoptotic signaling and neuronal degeneration in animal models [5-9]. In our current study, we analyzed carbonyl content in brain and blood/plasma samples from the same animals that have been used to evaluate oxidative and neurodegenerative effect of oxycodone reported in $[5,10]$. We demonstrated increased levels of protein carbonylation in rat cortex and also accumulation of Triton ${ }^{\mathrm{TM}}$ X-100 insoluble carbonyl-protein aggregates in blood plasma of animals treated with oxycodone, indicating a systemic degenerative process. Moreover, we developed a method to detect insoluble carbonylated protein aggregates in rat plasma that, we suggest, may be applied as a detection method of neuronal degeneration.

\section{Methods}

Animal model and tissue preparation

In this study, we have used tissue samples from female 60 day-old Sprague-Dawley rats that have been reported in our previous studies $[5,10]$. Briefly, randomly assigned animals were gavaged with vehicle water or with $15 \mathrm{mg} /$ $\mathrm{kg}$ oxycodone (Mallinckrodt Inc., St. Louis MO) in a volume of $1.0 \mathrm{ml} / \mathrm{kg}$ every $24 \mathrm{~h}$ for 30 days. Lack of toxicity and efficient anti-nociceptive effect of this oxycodone scheme treatment were assessed by daily weight measurement and by the hot plate tests, respectively, as it is described in $[5,10]$. We investigated tissues from twelve water and twenty oxycodone treated rats using from four sets of littermates. Experiments \# 1, 2, and 3 contained nine littermates each: three rats were gavaged with water and six animals gavaged with oxycodone. Experiment \# 4 contained five littermates: three rats treated with water and two rats treated with oxycodone. In the experiments \# 1 , 2, and 3 , brain tissues containing specific areas were pooled together from three rats in the same treatment group yielding one water brain lysate (W) and two oxycodone brain lysates (O1 and O2) for each experiment. In the experiment \#4, we analyzed brain lysate from individual animals (W1, W2, W3, O1 and O2). Brain lysate preparation is described in our earlier study [5]. Similarly, blood and plasma samples were prepared from pooled three corresponding rat samples in the same treatment group in the experiments \# 1,2 , and 3 , and from individual samples in the experiment \# 4 .

\section{Immunofluorescent staining of carbonylated proteins in rat brain}

Brain tissue preparation and immunofluorescent staining procedure were described elsewhere [5]. Briefly, in each experiment, water and oxycodone treated rats have been sacrificed on the same day by injection of $65 \mathrm{mg} / \mathrm{kg}$ i.p. of sodium pentobarbital and perfusion with ice-cold saline followed by $4 \%$ paraformaldehyde in $0.1 \mathrm{M}$ sodium phosphate buffer, $\mathrm{pH}$ 7.4. The whole brains were stored in $70 \%$ ethanol at $4{ }^{\circ} \mathrm{C}$ until further processing. Slides containing $10 \mu \mathrm{m}$ thick paraffin slices of cortex sections (plates 12-30, Rat Brain Atlas, Paxinos and Watson) were prepared as it is described in [5]. After deparaffinization, slides were incubated with 2,4-dinitrophenylhydrazine (DNPH) solution for $15 \mathrm{~min}$ at RT, blocked with horse serum for $1 \mathrm{~h}$ and then incubated with antiDNP antibodies (dilution 1:2000) in humidified chamber overnight at $4{ }^{\circ} \mathrm{C}$. Next morning, after wash with TBS-T (20 mM Tris- $\mathrm{HCl}, 150 \mathrm{mM} \mathrm{NaCl}$, and $0.1 \%$ Tween $^{\circledR} 20$, $\mathrm{pH} 7.5)$, slides were incubated with biotin-conjugated anti-goat IgG (dilution 1:200, Santa Cruz, cat \# sc-2042) for $2 \mathrm{~h}$ at RT and then with streptavidin conjugatedAlexaFlour $^{\circledR}-594$ (dilution 1:200, Life Technologies, cat \# 
S11227) for one hour at RT. Each brain slice was covered by VECTASHIELD HardSet Antifade Mounting Medium with DAPI (Vector Laboratories Inc., H-1500) and a cover slip. Images were visualized using AxioObserver with ApoTome microscope (Zeiss) as it is described in [5].

\section{BioVision assay}

Protein carbonyl groups in rat brain lysates were measured by the Protein Carbonyl Content Assay Kit (BioVision, Inc.) according to the manufacture's protocol. Briefly, one hundred microliters of cortex lysates with concentration $10 \mathrm{mg} / \mathrm{ml}$ were combined with $100 \mu \mathrm{l}$ $\mathrm{DNPH}$, vortexed and incubated for $10 \mathrm{~min}$ at room temperature (RT). Proteins were precipitated with $30 \mu \mathrm{l}$ trichloroacetic acid by centrifugation the samples at $20,000 \times g$ at $4{ }^{\circ} \mathrm{C}$ for $2 \mathrm{~min}$. Pellets were washed with cold acetone $\left(-20{ }^{\circ} \mathrm{C}\right)$, resuspended in $200 \mu$ l guanidine solution, briefly sonicated and then incubated at $60{ }^{\circ} \mathrm{C}$ for $30 \mathrm{~min}$. One hundred microliters aliquots were transferred to 96-well plate. Absorbance was measured at $375 \mathrm{~nm}$ in a microplate reader. Other five microliters aliquots were used to measure protein concentration in each sample by Micro BCA ${ }^{\mathrm{TM}}$ Protein Assay Kit (Thermo Scientific, Pierce) using BSA as a standard.

\section{Blood collection and plasma preparation}

Blood samples were collected from the same animals used for the brain lysate preparation described above. In the experiments \#1,2, and 3, each blood collection tube contained blood from three animals. For example, in the experiment \#1, the tube labeled "W" contained blood from three rats treated with water, "O1"-blood from three rats treated with oxycodone; and "O2"-another three rates treated with oxycodone. Total, the blood from 9 animals was used in the experiment \#1 (3 water and 6 oxycodone samples). Similarly, in the experiments $\# 2$ and 3, the blood from 9 animals was used in each experiment. In the experiment \#4, each blood collecting tube contained blood from one animal. Thus, each tube labeled W1, W2, and W3 contained blood from one animal treated with water. Each tube labeled O1 and $\mathrm{O} 2$ contained blood from one animal treated with oxycodone. Blood samples were collected in conical tubes containing $2 \mathrm{ml}$ buffer A per rat, supplemented with $0.1 \mathrm{mg} / \mathrm{ml}$ cycloheximide, $10 \mathrm{mg} / \mathrm{ml}$ heparin, Complete ${ }^{\mathrm{TM}}$ EDTA-free protease inhibitor cocktail (Roche) and phosphatase inhibitor cocktails (Pierce Biotechnology), on ice. Cells and plasma were separated by centrifugation at $1000 \times r p m$ at $4{ }^{\circ} \mathrm{C}$ for $5 \mathrm{~min}$. The supernatants (plasma) were collected and then protein concentration was determined using Micro BCA ${ }^{\mathrm{TM}}$ Protein Assay Kit.

\section{Dot-blot assay}

For dot blot analysis of protein carbonylation in rat blood plasma, samples containing twenty five to thirty micrograms of protein were incubated with equal volume of DNPH solution for $15 \mathrm{~min}$ at RT. After neutralization with Tris-Glycerol solution (2 M Tris and 30\% Glycerol), two microliters aliquots were spotted on a Nitrocellulose membrane (Bio-Rad) and then analyzed by incubation with anti-DNP antibodies (dilution 1:1000; Fitzgerald, 20R-DG001) overnight at $4{ }^{\circ} \mathrm{C}$ and then with anti-goat secondary antibodies (dilution 1:5,000) conjugated with horse-peroxidase (Vector Laboratories, Inc.) in $5 \%$ non-fat dry milk in TBS-T. Blots were developed as it is described in [5] using the Western Lightning ECL Pro development kit (PerkinElmer) and were exposed to HyBlot CL autoradiography film (Denville Scientific). The ImageQuant TL software (GE Healthcare Life Science) was used for quantitative analysis of dot blot images.

\section{Protein aggregation assay}

Aliquots containing eight hundred micrograms of total plasma protein were centrifuged at $20,000 \times g$ at $4{ }^{\circ} \mathrm{C}$ for $30 \mathrm{~min}$. Pellets were resuspended in $50 \mu \mathrm{l}$ buffer $\mathrm{C}$ (50 mM Tris- $\mathrm{HCl}, \mathrm{pH} 8.0,100 \mathrm{mM} \mathrm{KCl}$ ) supplemented with $1 \%$ Triton $^{\text {TM }} \mathrm{X}-100$, incubated on ice for $15 \mathrm{~min}$ and centrifuged again at $20,000 \times g$ at $4{ }^{\circ} \mathrm{C}$ for $30 \mathrm{~min}$. Resulting pellets were resuspended in $10 \mu \mathrm{l}$ buffer $\mathrm{C}$ supplemented with SDS. Five microliters aliquots of resuspended pellets were incubated with $5 \mu \mathrm{LNPH}$ reagent for $15 \mathrm{~min}$ at RT. Reactions were neutralized by adding $3 \mu \mathrm{l}$ Tris-Glycerol solution. Two microliters aliquots were then spotted on a Nitrocellulose membrane and then analyzed by anti-DNP antibodies as it is described in the Dot-blot assay section.

\section{Western blot analysis}

The western blot analysis was performed as it is described in $[5,10]$. Briefly, to analyse the expression of proteins in blood, equal amounts of total protein were loaded on a $12 \%$ or $4-12 \%$ NuPAGE $^{\circledR}$ Novex ${ }^{\circledR}$ Bis-Tris Gel (Invitrogen). To identify the position of specific proteins the Full-Range Rainbow protein molecular weight marker (GE Healthcare Life Science) was loaded on the same gel. After separation by the SDS-PAGE gel proteins were transferred to a Nitrocellulose membrane (Bio-Rad) using a Mini Trans-Blot cell (Bio-Rad). Membranes were incubated with primary antibodies: anti-P-eIF2 $\alpha$ (Ser51) (dilution 1:2000) and anti-eIF2 $\alpha$ (D7D3) XP (dilution 1:4000), all from Cell Signalling, at $4{ }^{\circ} \mathrm{C}$ for overnight. Anti-rabbit secondary antibodies conjugated with horseperoxidase (Vector Laboratories, Inc.) were diluted to 1:20,000. Signal detection and analysis were performed 
as it is described in $[5,10]$ using Western Lightning ECL Pro development kit (PerkinElmer), HyBlot CL autoradiography film (Denville Scientific) and the ImageQuant TL software (GE Healthcare Life Science). Results are presented as the mean of at least three independent treatment (drug administration) experiments \pm SEM.

\section{Statistical analyses}

The experiments were analysed blindly. All data and are presented as treatment means \pm SEMs $(n \geq 3)$. Statistical analysis was performed using a Student's t-test and oneway analysis of variance test ANOVA following Tukey's ranking tests. Data with p value lower than 0.05 was considered to be statistically different.

\section{Results}

Oxycodone increases protein carbonyl content in rat cortex To investigate whether chronic opioid administration increases the level of carbonyl-protein content in rat brain, we analyzed brain lysates of rats orally gavaged with $15 \mathrm{mg} / \mathrm{kg}$ of oxycodone every $24 \mathrm{~h}$ for 30 days. This study involves the same set of animals reported earlier $[5,10]$. The BioVision assay of brain lysates from nucleus accumbens, cortex and cerebellum revealed a significant increase in carbonyl content only in cortex lysates of oxycodone treated animals. Analysis of cortex lysates of rats from four different litters representing four different experiments demonstrated that, although the base level of protein carbonylation (water-treated animals) varied significantly between different rat litters, the relative increase in carbonyl signal in oxycodoneexposed tissues compared to that in water-treated rats in the same litter was reproducible in all four different experiments (Fig. 1a). On average, chronic oxycodone treatment increased the carbonyl-protein levels in rat brain tissues by $4.01 \pm 0.69$ fold $(\mathrm{p}=0.012)$ compare to that in water treated animals (Fig. 1a, right graph). We then investigated localization of carbonylated proteins in cortex areas of rats treated with water or oxycodone by immunofluorescent staining of brain slices derivatized with 2,4-dinitrophenylhydrazine (DNPH) (Fig. 1b). We observed increased numbers of DNP-labelled specks throughout of the cortex of oxycodone-exposed animals (14 to more than 50 specks per field) compared to that in water-treated cortex samples (0 to 5 specks per field) (Fig. 1b, upper images). Moreover, the size of such DNPlabelled specks also increased in oxycodone brain tissues (Fig. 1b, middle and lower images). Altogether, these data suggest that prolonged oxycodone administration is associated with accumulation of carbonyl-protein content in rat brain.

\section{Oxycodone induces insoluble protein aggregates in rat blood plasma}

Next, we investigated whether the changes in carbonylprotein content in the brain would correlate with the changes in blood plasma obtained from the same animals. Equal aliquots of plasma samples from the same animals that were tested for carbonyl content in the cortex (Fig. 1a) were derivatized, spotted on the nitrocellulose (NC) membrane and probed with antibodies against DNP (Fig. 2a, upper image) or stained with Ponceau $\mathrm{S}$ to detect the level of total protein in each spot (lower image). Within each experiment (representing the same litter), oxycodone-exposed plasma samples had higher carbonyl-protein content. However, statistical analysis of all three experiments showing about $1.51 \pm 0.16$ fold $(\mathrm{p}=0.1)$ increase in carbonyl content in oxycodoneexposed plasma compared to that in water-treated animals did not reach statistical significance (Fig. 2a, right graph).

In general, an increase in protein carbonyl content does not necessarily lead to cell death and degeneration. Carbonylation may act as a signal for protein degradation since carbonylated proteins are more susceptible to proteolytic degradation. It is only when heavily carbonylated proteins start to form aggregates that are resistant to degradation that they become toxic and can lead to cell death. Thus, we investigated whether chronic oxycodone administration is associated with accumulation of Triton $^{\mathrm{TM}} \mathrm{X}-100$ insoluble protein aggregates in plasma. Equal aliquots of plasma samples from the same animals as shown on Fig. $2 \mathrm{a}$ were centrifuged at $20,000 \times g$ for $30 \mathrm{~min}$. The pellets were resuspended in a buffer containing $1 \%$ Triton $^{\mathrm{TM}} \mathrm{X}-100$ and centrifuged again. Resulting pellets were dissolved in a buffer containing SDS, derivatized with DNPH and analysed by dot-blot (Fig. 2b). Remarkably, in all three experiments, dot-blot analysis showed a more than 2.8-fold statistically significant $(\mathrm{p}=0.017)$ increase in carbonyl-protein content in the Triton ${ }^{\mathrm{TM}} \mathrm{X}-100$ insoluble pellets from the oxycodone-exposed samples compared to that from the water-treated animals (Fig. 2b). These data suggest that chronic oxycodone exposure is associated with accumulation of Triton ${ }^{\mathrm{TM}} \mathrm{X}-100$ insoluble carbonylated proteins in blood plasma.

\section{Oxycodone induces the integrated stress response in rat blood}

In our previous study we demonstrated that chronic oxycodone administration is associated with activation of pro-apoptotic signaling, loss of white matter, reactivation of astrocytes [5] and induction of the integrated stress response (ISR) in rat brains [10]. In our current 


\section{a}
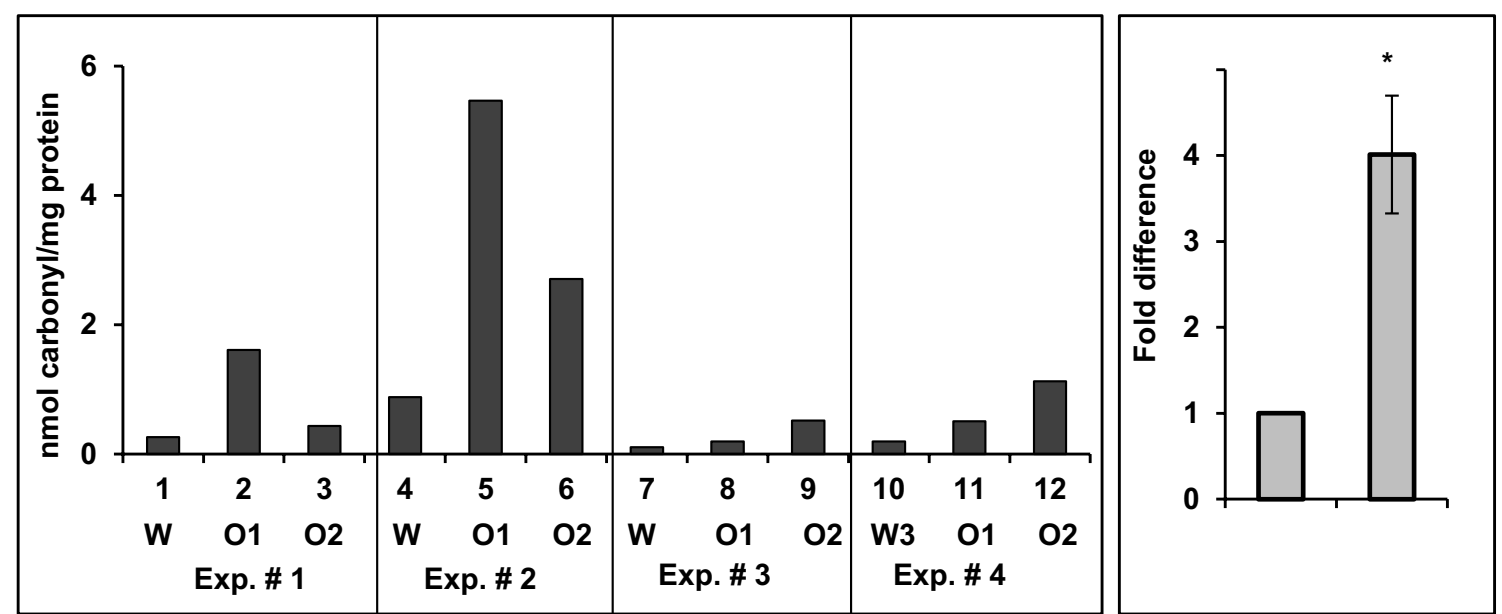

b

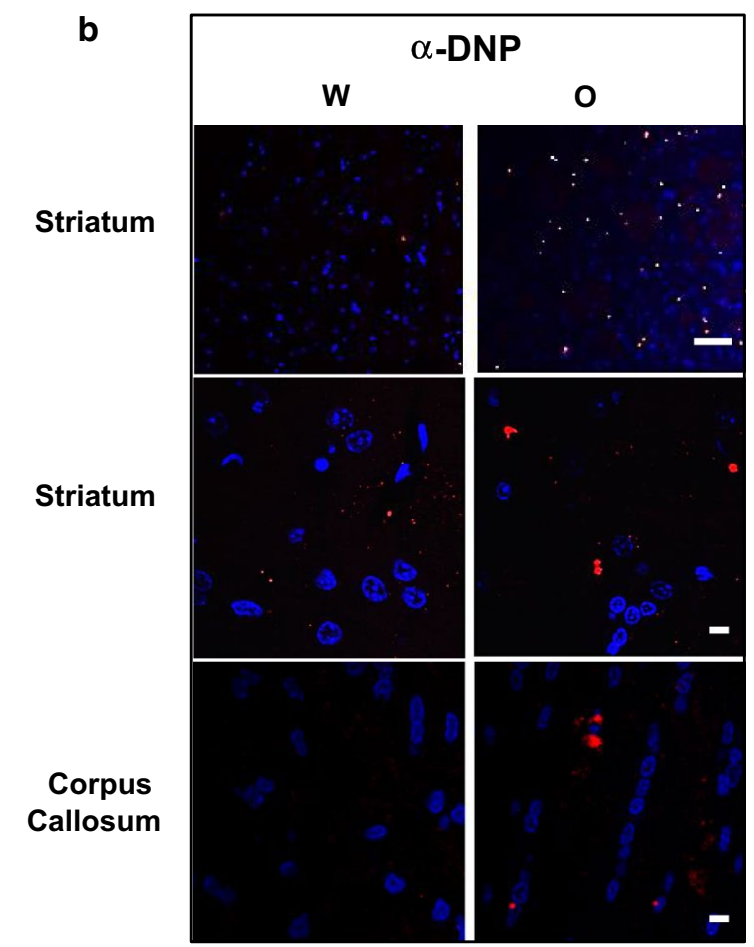

Fig. 1 Chronic oxycodone treatment increases protein carbonyl content in rat cortex. a BioVision carbonyl content assay of proteins from cortex lysates of rats treated with water $(\mathrm{W})$ or oxycodone $(\mathrm{O} 1, \mathrm{O} 2)$. Left panel, assay was performed according to a manufacture protocol using four sets of animal groups that represented four different litters, labeled as Exp. \#. Data expressed as nanomol of carbonyl groups per milligram of protein using BSA as standard. Right panel, graph representing mean value of carbonyl content in cortex lysates normalized to the corresponding water samples set as one for each experiment ( \pm SEM; $n=4$ (four BioVision experiments that analyzed samples from 10 water and 20 oxycodone treated rats; $p=0.012$ ). Statistical analysis of carbonyl content in oxycodone relative to water exposed cortex lysates was performed using Student's t-test. $\mathbf{b}$ Immunofluorescent analysis of carbonylated proteins in cortex of rats treated with water (W) or oxycodone (O). Scale bar denotes $50 \mu \mathrm{m}$ for the top striatum images and $5 \mu \mathrm{m}$ for the middle striatum and lower corpus callosum images

study of the tissues samples from the same animals, we observed an increase in the level of carbonyl-protein content in brain and blood plasma of oxycodone treated rats. What could trigger the neurotoxic signaling during prolonged oxycodone exposure? The ISR triggers a general adaption mechanism that provides necessary support for cells to survive during stress and also promotes recovery. However, under prolong stress conditions, 


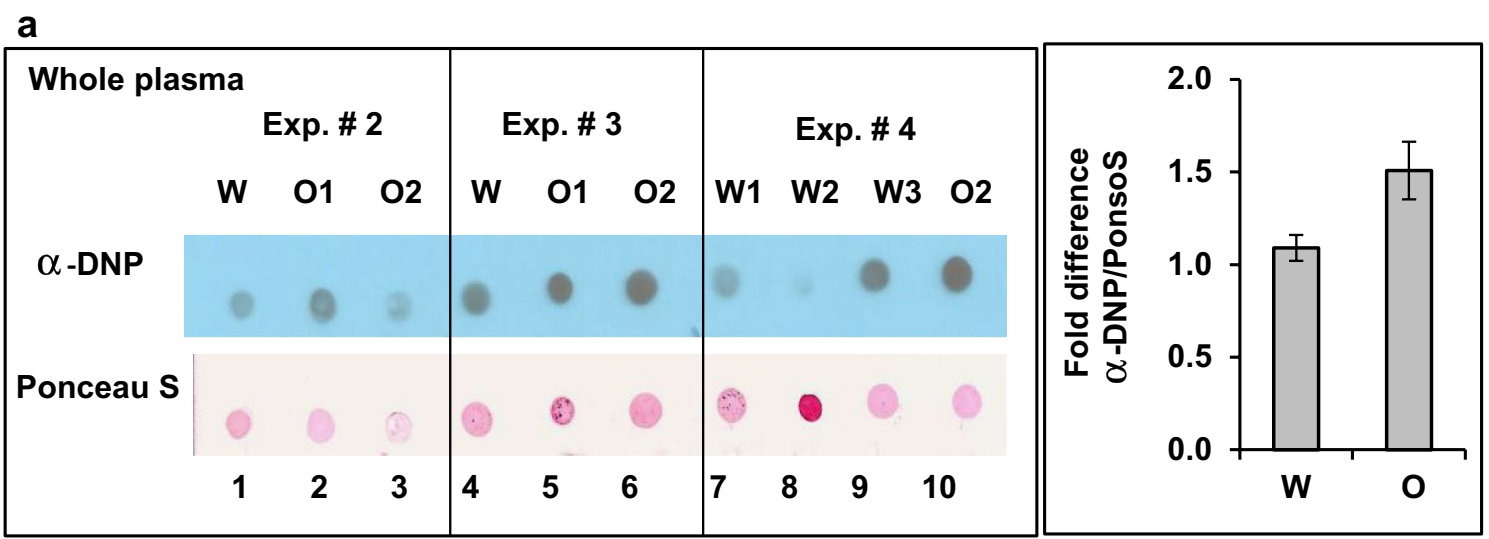

b

Triton $\mathrm{x}-100^{\mathrm{TM}}$ Insoluble plasma pellet

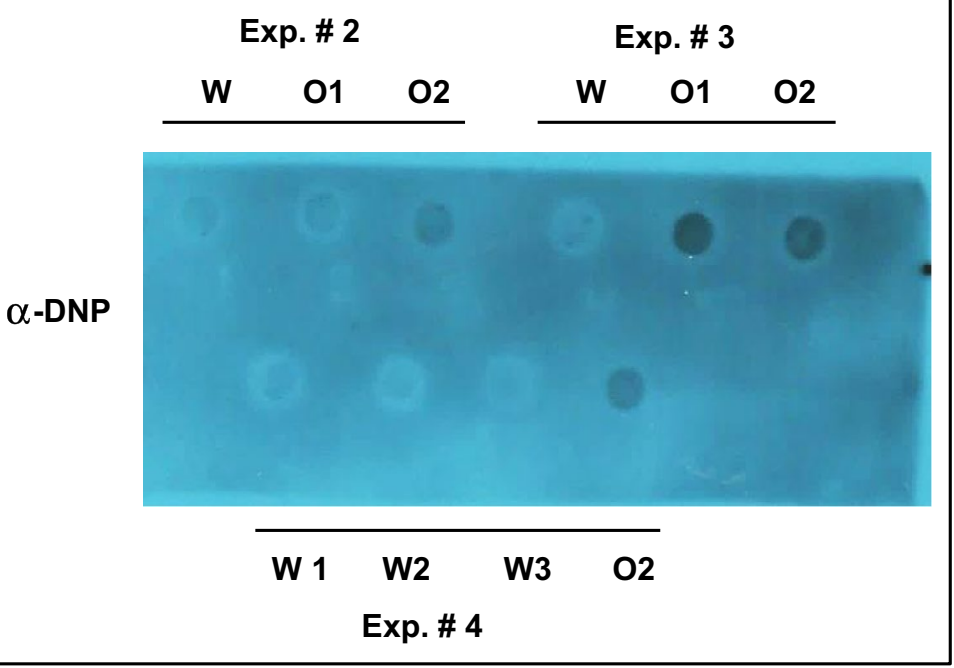

Fig. 2 Chronic oxycodone treatment increases protein carbonyl content in rat plasma. a Dot-blot analysis of carbonylated proteins in rat plasma. Left panel, equal amount of total protein from plasma of rats treated with oxycodone (O1, O2) or water (W) were derivatized with DNPH, spotted on NC membrane and probed with anti-DNP antibodies. The same membrane was later stained with Ponceau $\mathrm{S}$ to detect total protein in each spot. Each plasma sample corresponds to the same animal from which cortex samples was obtained (Fig. 1a, Exp. \#). The corresponding experiment is indicated above each set of samples. Right graph, quantitative analysis of dot-blot images shown on left. DNP signal was normalized to Ponceau S signal in corresponding sample and then oxycodone value was normalized to water value in the same experiment. Graph represents mean value of DNP to Ponceau S ratio normalized to water samples set as one ( \pm SEM; $n=3$ (three sets of experiments that analyzed samples from 9 water and 13 oxycodone treated rats; $\mathrm{p}=0.1)$. $\mathbf{b}$ Dot-blot analysis of Triton ${ }^{\mathrm{TM}} \mathrm{X}-100$ insoluble carbonylated proteins in rat plasma. Equal volume of plasma samples from rats treated with water $(\mathrm{W})$ or oxycodone $(\mathrm{O})$ corresponding to samples presented in a was centrifuged at $20,000 \times g$ for 30 min. The pellets were resuspended in buffer containing $1 \%$ Triton $^{\mathrm{TM}} \mathrm{X}-100$ and centrifuged again. Resulting pellets were dissolved in buffer, derivatized with DNPH, spotted on NC membrane and probed with anti-DNP antibodies

high expression of the ISR transcription factors ATF4 (cAMP element binding transcription factor 4 or activating transcription factor 4) and CHOP (DNA damage/C/ EBP homology protein) may lead to increase in protein synthesis and induce an accumulation of large molecular protein complexes, ATP depletion, oxidative stress and cell death [11-13]. To evaluate whether accumulation of carbonyl-protein aggregates correlates with induction of the ISR in blood we monitored the level of phosphorylated translation initiation factor 2 alpha (eIF $2 \alpha)$ in blood samples from the same animals (Fig. 3). Western-blot analysis showed almost $1.77 \pm 0.16$ fold statistically significant $(\mathrm{p}=0.048)$ increase in phospho-eIF $2 \alpha$ in oxycodone blood samples compared to that in water sample. These data suggest that prolonged activation of the ISR during opioid exposure may contribute to accumulation 


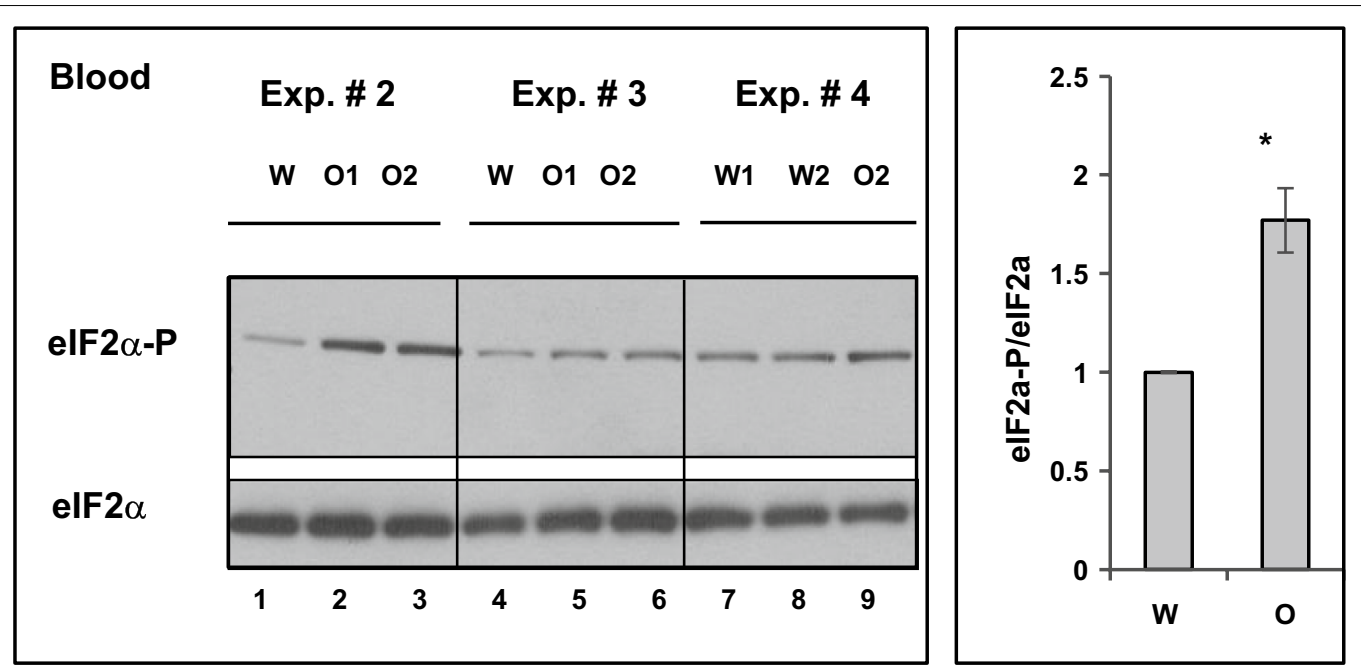

Fig. 3 Chronic oxycodone treatment activates the Integrated Stress Response in rat blood. Western blot analysis of phosphorylated elF2a in rat blood. Left panel, equal amount of total protein from blood of rats treated with oxycodone $(\mathrm{O} 1, \mathrm{O} 2)$ or water $(\mathrm{W})$ corresponding to samples presented in Fig. 2a. was analysed by western blot probed with anti-phospho elF2a and total elF2a. Right panel, graph representing mean value of phospho-elF2a to total elF2a ratio normalized to that in water samples set as one ( \pm SEM; $n=4$ water and $n=5$ oxycodone (three sets of experiments that analyzed samples from 8 water and 13 oxycodone treated rats; $p=0.048$ ). Statistical analysis of carbonyl content in oxycodone relative to water exposed cortex lysates was performed using Student's t-test

of carbonylated protein aggregates that eventually may lead to cellular degeneration.

\section{Discussion}

While the identification of biomarkers of neurodegeneration is critical to the early detection and treatment of adverse drug effects, currently there is no specific blood test to monitor the rate of degenerative disease progression at the level of the individual organism. The blood protein carbonylation assay may serve this purpose. It has been suggested that protein carbonylation may represent a sensitive biomarker of cellular degeneration due to excessive stress, aging, or certain pathologies [4] including Alzheimer's disease [14]. However, studies monitoring carbonyl protein content in clinical settings produced contradictory results. The reason for lack of "the protein carbonylation as a biomarker of degeneration" test on a market is that most of the studies have been measuring total (soluble and insoluble) carbonyl content in tissues or body fluids that may produce a false positive result and not always correlate with the degree of degeneration. In general, increase in protein carbonyl content does not necessarily lead to cell death and degeneration. It is only when excessive carbonyl content induces significant changes in protein structure leading to formation of protease resistant protein aggregates that become toxic and may lead to cell death (reviewed in [3]). Our data suggest that carbonyl protein aggregates may serve as a reliable biomarker of degeneration.
Previously we documented that chronic oxycodone administration associated with axonal degeneration and induction of oxidative and nitrosidative stresses and activation of the integrated stress response (ISR) in rat brain $[5,10]$. Since opioid abuse is associated with hypoxia, endoplasmic reticulum stress and the induction of excitotoxic stress, we have hypothesised that opioids cause systemic stress on the whole organism. Indeed, in current study we observed activation of the ISR in blood of animals chronically treated with oxycodone. The integrated stress response is a general mechanism that allows cells to adapt to various types of stresses [15]. The key event in the ISR, regardless of the trigger, is phosphorylation of eIF $2 \alpha$ that modulates expression and translational activation of specific mRNAs, such as ATF4 and CHOP, which determine whether the cell will adapt to the stress condition or undergo to apoptosis. However, under prolong stress conditions, elevated ATF4 and CHOP expression increases protein synthesis and thus causes accumulation of high molecular protein complexes, ATP depletion, oxidative stress and cell death [11-13]. Elevated eIF2 $\alpha$ phosphorylation was correlated with neuronal degeneration and was observed in the brain samples of Alzheimer's disease (AD) patients [16-19]. Thus, it is possible that prolonged activation of the ISR during opioid exposure results in accumulation of carbonylated protein aggregates that eventually lead to neuronal degeneration.

In our current study, we observed increase in carbonylated proteins in cortex areas and also accumulation of 
Triton X-100-insoluble carbonylated protein aggregates in rat blood plasma after prolonged oxycodone treatment. Recently, protein carbonylation and aggregation was linked to neuronal cell death in an animal model of experimental autoimmune encephalomyelitis characterized by central nervous system inflammation, demyelination and axonal degeneration [20].

\section{Conclusions}

Our data suggest that measuring amount of carbonylprotein content in insoluble fraction of blood may serve as a tool to monitor the rate of neuronal degeneration and degeneration in general in individual patient. Moreover, identification of unique proteins in these protein insoluble aggregates may facilitate development of a new diagnostic tool. This approach will help physicians and patients to evaluate current progression of the disease and efficiency of the therapy.

\section{Abbreviations}

ATF4: CAMP element binding transcription factor 4 or activating transcription factor 4; BSA: bovine serum albumin; CHOP: DNA damage/C/EBP homology protein, GADD153; CNS: central nervous system; DNPH: 2,4-dinitrophenylhydrazine; ISR: integrated stress response; NC: nitrocellulose; Oxy: oxycodone; RT: room temperature; $\mathrm{W}$ : water.

\section{Acknowledgements}

We thank the LSUHSC-S Animal Facility for maintaining rats, Department of Pharmacology, Toxicology, and Neuroscience for providing research space to work with animals, BRI for providing a laboratory space and equipment, Core Facility for assistance with the fluorescent microscope, and FW Cancer Center for assistance with tissue preparation. We thank Gabriel Johnson and Kasey Jackson for their technical assistance.

\section{Authors' contributions}

RF and SS performed the BioVision assay of brain samples and contributed to the data analyses. LMS planned, performed and oversaw RF and NLK in animal drug treatment, behavioral tests, and tissue isolation. TA provided valuable advice in experiment planning and data discussion. JF, DG and PLMCG provided valuable advice in data discussion and manuscript writing. NLK designed and monitored all experiments, contributed to the majority data presented and wrote the manuscript. All authors read and approved the final manuscript.

\section{Funding}

LMS was supported by Grant No. 2R01GM20818 from the National Institute of General Medical Sciences. The funding source had no role in study design; in the collection, analysis and interpretation of data; in the writing of the report; and in the decision to submit the article for publication.

\section{Availability of data and materials}

The datasets used and/or analyzed during the current study available from the corresponding author on reasonable request.

\section{Ethics approval and consent to participate}

All animal procedures were carried out in accordance with National Institutes of Health guide for the care and use of Laboratory animals. The protocol for animal studies was approved by the Louisiana State University Health Science Center, Institutional Animal Care and Use Committee. Protocol number P-12-029.

\section{Consent for publication}

Not applicable.

\section{Competing interests}

The authors declare that they have no competing interests.

\section{Author details}

${ }^{1}$ Department of Emergency Medicine, Louisiana State University Health Sciences Center, 1501 Kings Highway, Shreveport, USA. ${ }^{2}$ Department of Pharmacology, Toxicology, and Neuroscience, Louisiana State University Health Sciences Center, 1501 Kings Highway, Shreveport, USA.

Received: 25 March 2019 Accepted: 13 January 2020

Published online: 22 January 2020

\section{References}

1. Lee JS, Hu HM, Edelman AL, Brummett CM, Englesbe MJ, Waljee JF, Smer-

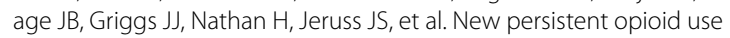
among patients with cancer after curative-intent surgery. J Clin Oncol. 2017;35(36):4042-9.

2. Upadhyay J, Maleki N, Potter J, Elman I, Rudrauf D, Knudsen J, Wallin D, Pendse G, McDonald L, Griffin M, et al. Alterations in brain structure and functional connectivity in prescription opioid-dependent patients. Brain. 2010;133(Pt 7):2098-114.

3. Nystrom T. Role of oxidative carbonylation in protein quality control and senescence. EMBO J. 2005;24(7):1311-7.

4. Levine RL. Carbonyl modified proteins in cellular regulation, aging, and disease. Free Radic Biol Med. 2002;32(9):790-6.

5. Fan R, Schrott LM, Arnold T, Snelling S, Rao M, Graham D, Cornelius A, Korneeva NL. Chronic oxycodone induces axonal degeneration in rat brain. BMC Neurosci. 2018;19(1):15.

6. Pu H, Wang X, Zhang J, Ma C, Su Y, Li X, Liu X, Su L. Cerebellar neuronal apoptosis in heroin-addicted rats and its molecular mechanism. Int J Clin Exp Pathol. 2015;8(7):8260-7.

7. Spain JW, Newsom GC. Chronic opioids impair acquisition of both radial maze and Y-maze choice escape. Psychopharmacology. 1991;105(1):101-6.

8. Mao J, Sung B, Ji RR, Lim G. Neuronal apoptosis associated with morphine tolerance: evidence for an opioid-induced neurotoxic mechanism. J Neurosci. 2002;22(17):7650-61.

9. Liu LW, Lu J, Wang XH, Fu SK, Li Q, Lin FQ. Neuronal apoptosis in morphine addiction and its molecular mechanism. Int J Clin Exp Med. 2013;6(7):540-5.

10. Fan R, Schrott LM, Snelling S, Ndi J, Arnold T, Korneeva NL. Chronic oxycodone induces integrated stress response in rat brain. BMC Neurosci. 2015;16:58.

11. Marciniak SJ, Yun CY, Oyadomari S, Novoa I, Zhang Y, Jungreis R, Nagata K, Harding HP, Ron D. CHOP induces death by promoting protein synthesis and oxidation in the stressed endoplasmic reticulum. Genes Dev. 2004;18(24):3066-77.

12. Galehdar Z, Swan P, Fuerth B, Callaghan SM, Park DS, Cregan SP. Neuronal apoptosis induced by endoplasmic reticulum stress is regulated by ATF4CHOP-mediated induction of the Bcl-2 homology 3-only member PUMA. J Neurosci. 2010;30(50):16938-48.

13. Han J, Back SH, Hur J, Lin YH, Gildersleeve R, Shan J, Yuan CL, Krokowski D, Wang S, Hatzoglou M, et al. ER-stress-induced transcriptional regulation increases protein synthesis leading to cell death. Nat Cell Biol. 2013;15(5):481-90.

14. Herbert MK, Verbeek MM, Kusters B, Kuiperij HB. A multifunctional ELISA to measure oxidised proteins: oxPin1 in Alzheimer's brain as an example. BBA Clin. 2015;4:1-6.

15. Ron D. Translational control in the endoplasmic reticulum stress response. J Clin Invest. 2002;110(10):1383-8.

16. Chang RC, Wong AK, Ng HK, Hugon J. Phosphorylation of eukaryotic initiation factor-2alpha (elF2alpha) is associated with neuronal degeneration in Alzheimer's disease. NeuroReport. 2002;13(18):2429-32.

17. O'Connor T, Sadleir KR, Maus E, Velliquette RA, Zhao J, Cole SL, Eimer WA, Hitt B, Bembinster LA, Lammich S, et al. Phosphorylation of the translation initiation factor elF2alpha increases BACE1 levels and promotes amyloidogenesis. Neuron. 2008;60(6):988-1009. 
18. Kim SM, Yoon SY, Choi JE, Park JS, Choi JM, Nguyen T, Kim DH. Activation of eukaryotic initiation factor-2 ?-kinases in okadaic acid-treated neurons. Neuroscience. 2010;169(4):1831-9.

19. Ma T, Trinh MA, Wexler AJ, Bourbon C, Gatti E, Pierre P, Cavener DR, Klann E. Suppression of elF2alpha kinases alleviates Alzheimer's disease-related plasticity and memory deficits. Nat Neurosci. 2013;16(9):1299-305. https ://doi.org/10.1038/nn3486.

20. Dasgupta A, Zheng J, Perrone-Bizzozero NI, Bizzozero OA. Increased carbonylation, protein aggregation and apoptosis in the spinal cord of mice with experimental autoimmune encephalomyelitis. ASN Neuro. 2013;5(1):e00111.

\section{Publisher's Note}

Springer Nature remains neutral with regard to jurisdictional claims in published maps and institutional affiliations.
Ready to submit your research? Choose BMC and benefit from:

- fast, convenient online submission

- thorough peer review by experienced researchers in your field

- rapid publication on acceptance

- support for research data, including large and complex data types

- gold Open Access which fosters wider collaboration and increased citations

- maximum visibility for your research: over $100 \mathrm{M}$ website views per year

At BMC, research is always in progress.

Learn more biomedcentral.com/submissions 